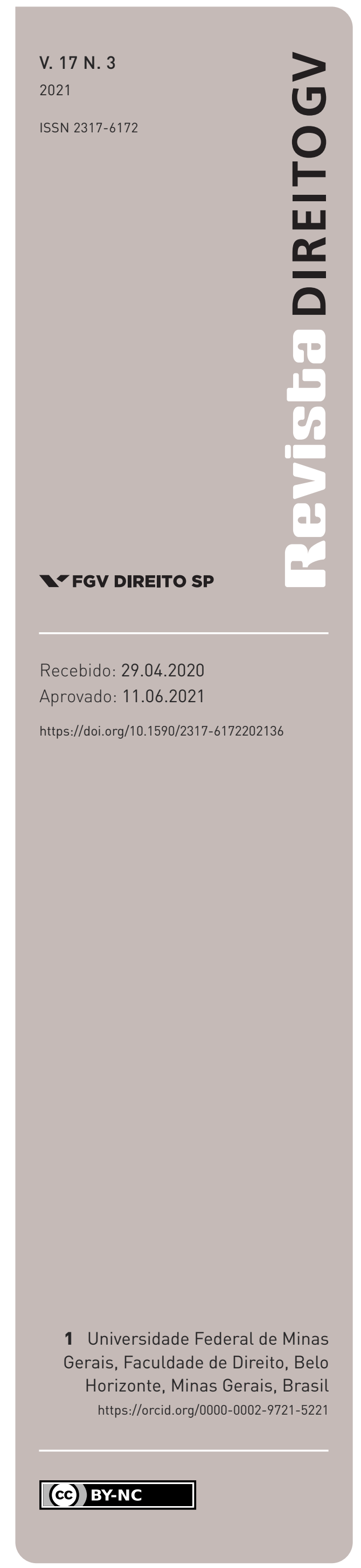

\section{Direitos sexuais e reprodutivos ou direitos sexuais e direitos reprodutivos? Dilemas e contradições nos marcos normativos nacionais e internacionais}

\author{
SEXUAL AND REPRODUCTIVE RIGHTS OR SEXUAL RIGHTS AND REPRODUCTIVE RIGHTS? \\ DILEMMAS AND CONTRADICTIONS IN THE INTERNATIONAL AND THE BRAZILIAN LEGAL \\ FRAMEWORK \\ Juliana Cesario Alvim Gomes'
}

\section{Resumo}

Nas últimas décadas, desdobramentos jurídicos relativos à sexualidade e à identidade de gênero vêm sendo reconhecidos tanto nacional quanto internacionalmente. Nesse contexto, apesar dos esforços para a construção e consolidação de um conteúdo autônomo, os direitos sexuais com frequência são reivindicados a partir do tratamento conjunto de "direitos sexuais e reprodutivos". 0 presente artigo busca demonstrar que, historicamente, sobretudo a partir das conferências internacionais da década de 1990, esse tratamento indiferenciado entre direitos sexuais e reprodutivos colaborou para que os primeiros passassem a ser vistos como uma categoria subordinada e condicionada aos segundos. Esse processo, embora tenha sido objeto de críticas pela literatura, não foi revertido no emprego do termo pelo poder público no Brasil. À luz dessas considerações, o artigo busca apontar a utilidade da categoria autônoma dos direitos sexuais para a proteção e promoção de direitos relativos à sexualidade e identidade de gênero. De maneira mais ampla, tem por objetivo evidenciar alguns dos riscos que uma visão que desconsidere as características de interdependência e indivisibilidade dos direitos humanos pode acarretar.

\section{Palavras-chave}

Direitos sexuais; direitos reprodutivos; conferências internacionais; gênero; sexualidade.

\begin{abstract}
In recent decades, legal developments regarding the field of sexuality have been recognized both nationally and internationally. In this context, sexual rights are often claimed based on the joint treatment of "sexual and reproductive rights", despite efforts to build and consolidate an autonomous content. Historically, this undifferentiated treatment between sexual and reproductive rights collaborated so that the former came to be seen as a subordinate and conditioned category to the latter. Despite the criticisms, this process has not been reversed on the political and constitutional level in Brazil. In the light of these considerations, the article aims to point out the usefulness of the category of sexual rights for the protection and promotion of rights related to sexuality and gender identity. It also aims to signal the risks of a fragmentary view of human rights that does not consider them in an indivisible and interdependent way.
\end{abstract}

\section{Keywords}

Sexual rights; reproductive rights; human rights; gender; sexuality. 


\section{INTRODUÇÃO}

Nas últimas décadas, a relevância dos desdobramentos jurídicos relativos à sexualidade e à identidade de gênero vem sendo reconhecida tanto no âmbito nacional quanto no internacional. Internacionalmente, esse processo vem sendo acompanhado da consolidação do uso da expressão "direitos sexuais" para promover essa categoria de direitos.

O uso dessa expressão busca articular conjuntamente múltiplas demandas relativas à sexualidade e à identidade de gênero abarcando-as sob a gramática e o regime jurídico geral dos direitos fundamentais e humanos. Ao mesmo tempo, visa a conferir proteção e legitimidade a identidades, práticas e comportamentos que não estão necessariamente ligados nem à saúde, nem à reprodução, alcançando indivíduos e grupos tradicionalmente desconsiderados como sujeitos de direitos.

Apesar dos esforços para a construção e consolidação de um conteúdo autônomo, os direitos sexuais são, com frequência, mobilizados a partir do tratamento conjunto de "direitos sexuais e reprodutivos". O presente artigo busca demonstrar que essa abordagem indiferenciada impactou negativamente o avanço de pautas relativas à sexualidade e à identidade de gênero, marginalizando práticas, identidades e agendas não hegemônicas.

Para tanto, será realizada uma análise da trajetória histórica do conceito, com ênfase nas conferências internacionais da década de 1990. Como se verá adiante, apesar dos inegáveis avanços verificados nas sucessivas conferências, o tratamento da sexualidade permaneceu vinculado à saúde e/ou atrelado aos direitos reprodutivos de casais cis-heterossexuais. Além disso, a viabilização dos avanços no campo da saúde sexual e dos direitos reprodutivos ocorreu à custa da domesticação da ideia de sexualidade, em que aspectos considerados mais controversos foram utilizados como moeda de troca durante barganhas políticas ocorridas nas conferências - até serem, finalmente, excluídos. Essas contradições refletiram-se na fragmentação das abordagens sobre sexualidade e identidade de gênero nos anos 2000, em franca contrariedade às ideias de indivisibilidade, inter-relação e interdependência dos direitos humanos. Nesse contexto, um tratamento indiferenciado entre direitos sexuais e reprodutivos colaborou para que os primeiros passassem a ser vistos como uma categoria subordinada e condicionada aos segundos.

Esse processo vem sendo objeto de crítica por parte da literatura nacional e estrangeira. Como se verificará, no plano nacional o debate em torno dos direitos sexuais surge a partir da Conferência de Beijing, em meados dos anos 1990, e, desde as publicações pioneiras, já trata de maneira crítica da indiferenciação entre direitos sexuais e reprodutivos.

Entretanto, como se demonstrará a partir da análise de atos normativos do Poder Executivo federal, leis e projetos de lei no âmbito da Câmara dos Deputados e do Senado Federal e decisões proferidas pelo Supremo Tribunal Federal (STF) e pelo Superior Tribunal de Justiça (STJ) até 2019, apesar das profícuas discussões em torno da categoria dos direitos sexuais por parte da literatura, seu uso é muito rarefeito no âmbito do poder público no Brasil. Isso se verifica mesmo em contextos em que direitos relativos à sexualidade e à identidade 
de gênero foram amplamente discutidos, como na promulgação do Plano Nacional de Promoção da Cidadania e Direitos Humanos LGBT pelo Poder Executivo em 2009 e em julgamentos do STF, como aquele em que foram afirmados: a constitucionalidade das uniões homoafetivas, em 2011; o direito de pessoas trans à retificação de nome e sexo no registro civil, em 2018; e a criminalização da LGBTfobia, em 2019. Ademais, nas raras vezes em que a expressão é empregada, em regra, o é por meio de um tratamento indistinto em relação aos direitos reprodutivos.

Nesse contexto, o artigo busca apontar a utilidade da categoria autônoma dos direitos sexuais para proteção e promoção de direitos relativos à sexualidade e à identidade de gênero, ao lançar luzes sobre aspectos tradicionalmente negligenciados pela utilização indiferenciada na expressão "direitos sexuais e reprodutivos" e possibilitar uma visão positiva e emancipatória de sexualidade e identidade de gênero. O trabalho pretende, ainda, de maneira mais ampla, evidenciar alguns dos riscos em que pode incorrer uma visão dos direitos humanos que não os considere de maneira complexa, interdependente e indivisível.

\section{DiREITOS SEXUAIS NO PLANO INTERNACIONAL}

\section{I. DiREITOS SEXUAIS: DEFINIÇÃO ATUAL}

Desde os anos 2000, documentos internacionais têm buscado definir e sistematizar os chamados direitos sexuais. Dentre os mais importantes ${ }^{1}$ estão os Princípios de Yogyakarta sobre orientação sexual e identidade de gênero, redigidos e aprovados por um conjunto de 29 especialistas (THE YOGYAKARTA PRINCIPLES, 2006), a declaração da organização não governamental International Planned Parenthood Federation (IPPF, 2008) e a Declaração sobre Direitos Sexuais da World Association for Sexual Health (WAS, 2014), organização internacional que reúne sociedades sexológicas e sexólogos, de 2014.

Como se depreende desses documentos, os direitos sexuais se definem pelo seu objeto a sexualidade e a identidade de gênero. ${ }^{2}$ Os direitos que sobre ele incidem são muitas vezes

1 Alice M. Miller, Eszter Kismödi, Jane Cottingham e Sofia Gruskin (2015) incluem também como documentos canônicos em matéria de direitos sexuais a compilação de casos e leis sobre orientação sexual e identidade de gênero da International Commission of Jurists (2011) e relatórios da Organização Mundial da Saúde (2015). Lottes (2013, p. 373) chama atenção para dois documentos anteriores que, no entanto, enfocavam apenas direitos das mulheres: um da organização Colombiana Women's Global Network for Reproductive Rights de 1996 e outro do subgrupo HERA (Health, Empowerment, Rights, and Accountability) da International Women's Health Coalition. A autora ainda traz outros, como a Declaração de Valência de Direitos Sexuais, apresentada em 1999 no âmbito da Associação Mundial de Sexologia.

2 Miller et al. (2015, p. 17) chamam atenção para o fato de que "a forma como cada um expressa gênero pode formar a base sobre a qual o direito estatal regula com quem essa pessoa pode ter relações sexuais 
direitos já consagrados nas constituições e nos tratados internacionais de direitos humanos. Nesse sentido, a declaração da IPPF afirma que "os direitos sexuais são compreendidos por um conjunto de direitos relacionados à sexualidade que emanam dos direitos à liberdade, igualdade, privacidade, autonomia, integridade e dignidade de todas as pessoas". A conhecida definição de trabalho da Organização Mundial da Saúde (OMS), de 2002, prevê, por sua vez, que "Os direitos sexuais abarcam certos direitos humanos que já estão reconhecidos em tratados de direitos humanos internacionais e regionais, baseados em documentos de consenso e encontrados no direito doméstico" (WHO, 2010).

Isso não significa, contudo, que o resultado da incidência de direitos consagrados sobre sexualidade e identidade de gênero não traga desdobramentos novos e particulares, que são essenciais para a concretização desses direitos. A Declaração dos Direitos Sexuais da WAS ilustra esse fenômeno. Ao mesmo tempo em que abarca, por exemplo, o direito à saúde, à educação e o "direito de estar isento de todas as formas de violência ou coerção", inclui em seu texto repercussões e exigências específicas. Veja-se:

[a proteção ao] estupro, abuso ou, perseguição sexual, "bullying", exploração sexual e escravidão, tráfico com propósito de exploração sexual, teste de virgindade ou violência cometida devido à prática sexual real ou presumida, orientação sexual, identidade e expressão de gênero ou qualquer característica física (artigo 5);

o direito ao mais alto padrão de saúde atingível, inclusive de saúde sexual; com a possibilidade de experiências sexuais prazerosas, satisfatórias e seguras (artigo 7); e

o direito à educação e o direito à educação sexual esclarecedora (artigo 10). (WAS, 2014)

Outro aspecto importante é que os direitos sexuais possuem múltiplas dimensões, incluindo de prestação e de proteção, individuais e coletivas, oponíveis ao Estado e também a particulares. Em verdade, os direitos sexuais consistem em um rol aberto e não taxativo de direitos relativos à sexualidade e à identidade de gênero, que têm sido conceituados e desenvolvidos ao longo do tempo a partir de compreensões, entendimentos, demandas e mobilizações concretas.

legítimas”. Além disso, a identidade de gênero é, em geral, determinante para condicionar limites e possibilidades das experiências sexuais às quais o indivíduo está sujeito, sejam elas positivas, sejam negativas. Apesar dessa conexão entre sexualidade e identidade de gênero e da articulação histórica conjunta desses dois aspectos (seja por parte de sujeitos e movimentos, seja por parte do aparato médico e jurídico), seu tratamento indiferenciado sob a rubrica dos "direitos sexuais" merece um estudo específico que leve em conta se e em que medida esse tratamento não contribuiu/contribui para um protagonismo de demandas relativas à sexualidade em detrimento daquelas concernentes à identidade de gênero. 
Nesse sentido, o preâmbulo dos Princípios de Yogyakarta prevê a necessidade de revisões periódicas do documento para "permitir a incorporação de desenvolvimentos no direito e na sua aplicação para vidas particulares e experiências de pessoas de orientação sexual e identidades de gênero diversas ao longo do tempo em diversas regiões e países”. Em consonância com essa previsão, em 2017 realizou-se atualização de tais princípios que incorporou ao texto original nove princípios adicionais e onze novas obrigações estatais (Yogyakarta Principles plus $10-\mathrm{YP}+10)$.

Embora os direitos sexuais se comuniquem com os direitos reprodutivos, com eles não se confundem. Por um lado, pode haver sexualidade sem reprodução (por exemplo, com uso de métodos anticoncepcionais, no caso de relações entre pessoas do mesmo sexo ou, ainda, de pessoas que, por alguma razão, não possam individual ou conjuntamente conceber). E, por outro, reprodução sem sexualidade (por exemplo, por meio de técnicas de reprodução assistida). É verdade, contudo, que alguns direitos estão localizados na interseção entre os dois conjuntos. É o caso, por exemplo, do direito ao acesso à contracepção e ao aborto. A decisão de iniciar, continuar ou terminar uma gravidez pode ser vista tanto como uma escolha reprodutiva quanto "como um aspecto da capacidade da mulher [e do homem trans] de conectar ou desconectar a atividade sexual da decisão de se tornar mãe [/pai]" (MILLER et al., 2015, p. 17, inclusão nossa), estando no campo da sexualidade a depender do aspecto enfatizado. Os direitos sexuais são, portanto, direitos relacionados à sexualidade e à identidade de gênero independentemente de qualquer dimensão reprodutiva.

Essa categoria é relevante, por um lado, por ser capaz de articular conjuntamente múltiplas demandas relativas à sexualidade e à identidade de gênero, abarcando-as sob a gramática e sob o regime jurídico geral dos direitos fundamentais e humanos. Por outro, por conferir proteção e legitimidade a identidades, práticas e comportamentos sexuais que não estão necessariamente ligados nem à saúde, nem à reprodução, alcançando indivíduos e grupos tradicionalmente excluídos como sujeitos de direitos relativos à sexualidade e à identidade gênero. Como afirma Ignacio Saiz (2004, p. 65), os direitos sexuais permitem, a partir de uma lógica de universalidade, articular diversas perspectivas, incluindo "direitos das mulheres, população e desenvolvimento, saúde reprodutiva, HIV/AIDS, e direitos de gays lésbicas e transgêneros"; abarcar e promover "uma visão mais positiva e emancipatória da sexualidade", sujeita não apenas à proteção "contra violência e interferência, mas também como um bem social a ser respeitado, protegido e alcançado"; articular interseções entre diferentes restrições à sexualidade a fim de identificar "causas comuns de diferentes formas de opressão"; e "construir pontes e coalizões entre movimentos diversos para enfrentar obstáculos comuns (como o fundamentalismo religioso)" (SAIZ, 2004, p. 65).

Apesar dos esforços para a construção e consolidação de um campo autônomo para os direitos sexuais - que se refletem nos documentos mencionados acima -, até hoje não existe um tratado internacional vinculante que cuide, especifica e autonomamente, da questão. Como se verá adiante, com frequência os direitos sexuais são reivindicados a partir do 
tratamento conjunto de "direitos sexuais e reprodutivos", sobretudo no âmbito doméstico, em que o uso da categoria é mais incipiente. Esse tratamento indiferenciado pode gerar uma série de efeitos negativos que comprometem a proteção da sexualidade e da identidade de gênero.

\section{I.2.TRAJETÓRIA DOTRATAMENTO NORMATIVO DA SEXUALIDADE}

A literatura registra que a expressão "direitos sexuais" começou a ser empregada no contexto normativo no plano internacional a partir da década de 1990 (CORRÊA e HOWE, 2007, p. 171). ${ }^{3}$ Entretanto, isso não significa que temas relacionados à sexualidade não viessem sendo tratados naquele âmbito muito antes disso.

Alice Miller (1999, p. 288) chama atenção, particularmente, para os mais de "noventa anos de tentativas de tratados internacionais em controlar o cruzamento de fronteiras por pessoas para fins de prostituição”. Segundo a autora, a abordagem inicial da sexualidade no âmbito internacional tendia a privilegiar sexualidades dominantes a partir de uma perspectiva de controle ou proteção, elementos que estavam incluídos em discursos como aqueles presentes nas convenções que tratavam de "escravidão branca", conceito utilizado à época para se referir ao tráfico internacional de mulheres para fins de prostituição - que, ao mesmo tempo, excluía mulheres não brancas de sua esfera de proteção e formatava o que seria uma "boa" sexualidade ao abordar a violência sexual como "um ataque à honra de uma mulher" (MILLER, 1999, p. 292; 2000, p. 77).

Já aqui se observam contradições no tratamento jurídico da sexualidade. A pretexto de promover a proteção de mulheres, a sexualidade de mulheres não brancas é rebaixada e desconsiderada como objeto de proteção. Ao mesmo tempo, o exercício legítimo da sexualidade da mulher é condicionado àquilo que é "honrado", em oposição a manifestações de sexualidade consideradas desviantes. Em paralelo, são construídos discursos que demonizam certos homens a partir de estereótipos baseados em raça e nacionalidade e os retratam como perigosos e ameaçadores à pureza dessa mulher (branca), que deve ser protegida (LAMMASNIEMI, 2017).

Ao longo do século XX, outros aspectos da sexualidade e da identidade de gênero passaram a ser, progressivamente, abordados em espaços judiciais e não judiciais internacionais e regionais de direitos humanos, sobretudo a partir da década de 1990. Questões como violência sexual em conflitos armados, assim como escravidão sexual, foram discutidas já durante

3 Ilsa Lottes (2013, p. 371) chama atenção para o fato de que a expressão já havia sido utilizada em contextos domésticos anteriormente, como no Projeto de Lei sobre Direitos Sexuais e Responsabilidades, redigido por Lester Kirkendall e publicado em uma edição de 1976 da revista The Humanist, e no final da década de 1980, nas políticas de saúde e educação dos Países Baixos, da Dinamarca e da Suécia. A autora ressalta, contudo, que, "não obstante, apenas após a ICPD [Conferência Internacional sobre População e Desenvolvimento] o termo direitos sexuais foi destacado em publicações nórdicas". 
a elaboração do Estatuto de Roma, que deu origem ao Tribunal Penal Internacional, e também a partir de casos que tratavam de genocídios como os ocorridos na antiga Iugoslávia e em Ruanda (MACKINNON, 1998, 2006).

Do mesmo modo, sistemas regionais de direitos humanos passaram a decidir casos que tratavam sobre os referidos temas. Desde o fim da década de 1980, a Corte Europeia de Direitos Humanos vem decidindo casos relacionados a abuso sexual, ${ }^{4}$ criminalização da homossexualidade $^{5}$ e identidade de gênero de pessoas trans, tendo havido, com relação a esse último conjunto, alteração da jurisprudência nos anos 2000, a partir de quando se passou a reconhecer tais direitos, anteriormente negados (ECHR, 2018a). Ao longo dos anos, outros assuntos passaram a ser decididos pela referida corte, como orientação sexual ${ }^{6}$ e divulgação pública de informações médicas individuais. ${ }^{7}$ No âmbito do Sistema Interamericano de Direitos Humanos, destacam-se casos relativos a violência sexual (ALENCAR, 2017) e a direitos LGBT (RIOS et al., 2017) que começaram a ter sua admissibilidade reconhecida a partir do final da década de 1990.

No sistema da Organização das Nações Unidas (ONU), o caso Toonen v. Australia é considerado paradigmático. Na ocasião, em 1994, o Comitê de Direitos Humanos declarou que

4 Um dos casos pioneiros sobre estupro foi $X$ and $Y_{v}$. the Netherlands, de 26 de março de 1985. Para outros casos sobre abuso sexual de crianças e adolescentes, cf. ECHR (2011).

5 Cf. Dudgeon v. the United Kingdom, de 22 de outubro de 1981, e Norris v. Ireland, de 26 de outubro de 1988. Para mais casos, cf. ECHR (2014).

6 Em 1999, decidiu que homem homossexual vivendo com outro homem tinha direito de visitar sua filha que vivia com sua ex-esposa (Salgueiro da Silva Mouta v. Portugal, de 21 de dezembro de 1999) e que investigação sobre sexualidade de membros das forças armadas que resultou em sua exclusão violava a Convenção Europeia de Direitos Humanos (Lustig-Prean and Beckett v. the United Kingdom e Smith and Grady v. the United Kingdom, de 27 de setembro de 1999) (ECHR, 2018b). A Corte Europeia de Direitos Humanos, após decidir, em 2010, que os Estados europeus não são obrigados a permitir casamentos entre pessoas do mesmo sexo devido "às conotações sociais e culturais profundamente enraizadas que podem diferir amplamente de uma sociedade para a outra" (Schalk and Kopf v. Austria, de 22 de novembro de 2010), entendeu, em 2013, que o Código Civil da Áustria discriminava homossexual por impossibilitar a adoção de filho biológico de seu parceiro, enquanto permitia esse tipo de adoção para casais heterossexuais não casados ( $\mathrm{X}$ and others v. Austria, de 19 de fevereiro de 2013). No mesmo ano, duas outras importantes decisões foram tomadas no âmbito europeu: a que garantiu o direito de homossexuais constituírem uma família juridicamente reconhecida, invalidando lei grega sobre uniões estáveis que contemplava exclusivamente relacionamentos estáveis entre um homem e uma mulher (Case of Vallianatos and Others v. Greece, de 7 de novembro de 2013), e, no Tribunal de Justiça da União Europeia, a que decidiu que um estrangeiro homossexual que corra risco de perseguição no seu país de origem tem direito de receber asilo na Europa (Tribunal de Justiça da União Europeia, C 199/12 a C 201/12, 4ª Seção, 7 de novembro de 2013).

7 Em 1997, condenou a Finlândia em razão do vazamento da condição de portadora de HIV da aplicante em um contexto de procedimentos relativos a abuso sexual (Z. v. Finland, de 25 de janeiro de 1997). 
as leis australianas que criminalizavam a sodomia violavam o Pacto Internacional sobre Direitos Civis e Políticos, especificamente seu art. 17, relativo à privacidade, e seu art. 26, concernente à igualdade e à vedação de discriminação, que, por sua vez, deveria ser interpretado de forma a incluir "orientação sexual” entre os critérios cuja utilização para discriminar seria proibida. A partir dessa decisão, outros órgãos de monitoramento da ONU passaram a tratar do tema da orientação sexual. Além do próprio Comitê de Direitos Humanos, o Comitê de Direitos Econômicos Sociais e Culturais e o Comitê para a Eliminação da Discriminação contra a Mulher se manifestaram em questões como criminalização da homossexualidade, maus-tratos a LGBTs encarcerados, abusos contra a liberdade de associação e ao direito de proteção policial de ativistas LGBTs, impactos da orientação sexual na fruição de direitos como trabalho, habitação, saúde e acesso à água, entre outras (SAIZ, 2004, p. 51). Segundo Ignacio Saiz (2004, p. 53), "todos os tratados de direitos humanos mais importantes podem e têm sido invocados para desafiar uma miríade de violações baseadas em orientação sexual e identidade de gênero". Para além dos órgãos de monitoramento de tratados, relatórios de experts para analisar determinados temas ou países também contribuíram para consolidar a sexualidade como um direito humano (SAIZ, 2004, p. 54; MILLER, 1999, p. 289-290).

Igualmente, desde a década de 1990, conferências mundiais e organizações não governamentais nacionais e internacionais têm chamado atenção para questões de direitos humanos, gênero e sexualidade. Foi no âmbito dessas conferências que a utilização da expressão "direitos sexuais" começou a ganhar notoriedade.

\section{I.3. AS CONFERÊNCIAS INTERNACIONAIS DA DÉCADA DE $199^{\circ}$}

Em 1993, a II Conferência Internacional de Direitos Humanos, realizada em Viena, deu origem à Declaração e ao Programa de Ação de Viena. Ao tratar da temática da sexualidade, dispõe que "A violência e todas as formas de abuso e exploração sexual, incluindo o preconceito cultural e o tráfico internacional de pessoas, são incompatíveis com a dignidade e valor da pessoa humana e devem ser eliminadas" (parágrafo 18), ressalta a necessidade de "eliminar todas as formas de assédio sexual, exploração e tráfico de mulheres" e inclui atos de caráter sexual, como "estupros sistemáticos, escravidão sexual e gravidez forçada" em conflito armado, como "violações de princípios fundamentais dos instrumentos internacionais de direitos humanos e do direito humanitário" (parágrafo 38). Além de abordar direitos das mulheres, determina que "A exploração e o abuso de crianças devem ser ativamente combatidos, atacando-se suas causas" e busca combater "a prostituição infantil, a pornografia infantil e outras formas de abuso sexual” (parágrafo 48$){ }^{8}$

8 O parágrafo 21 estabelece ainda o fortalecimento dos mecanismos de proteção à infância em especial, 
Essa conferência, no que tange ao tratamento da sexualidade, segue a linha do que estava estabelecido em convenções anteriores. Desde 1979, a Convenção sobre a Eliminação de Todas as Formas de Discriminação contra a Mulher (Convenção CEDAW) dispunha sobre a obrigação dos Estados-partes de tomarem "todas as medidas apropriadas, inclusive de caráter legislativo", para "suprimir todas as formas de tráfico de mulheres e exploração da prostituição da mulher" (art. $6^{\circ}$ ). A Convenção Internacional sobre os Direitos da Criança, por sua vez, determinava desde 1989 o combate a "maus-tratos ou exploração, incluindo a violência sexual” (art. 19, 1), e à exploração e ao abuso sexual, incluindo a prostituição e a pornografia infantis (art. 34). A Conferência de Viena inova, contudo, ao estabelecer que o estupro em situações de guerra é "um crime contra os direitos humanos" (CORRÊA, 2001, p. 30).

No ano seguinte, 1994, com a Conferência Internacional sobre População e Desenvolvimento (Conferência do Cairo), a questão da saúde sexual entrou na agenda dos direitos humanos. O Programa de Ação da conferência traz um capítulo dedicado a direitos e saúde reprodutiva, que dispõe sobre informação, educação e assessoramento em matéria de sexualidade humana, saúde reprodutiva e paternidade responsável, planejamento familiar, doenças sexualmente transmissíveis e prevenção do vírus da imunodeficiência adquirida (HIV) e saúde reprodutiva e sexual de adolescentes, em especial gravidez não desejada, aborto em más condições e doenças sexualmente transmissíveis. Contém, ainda, previsões relativas à educação sexual e à proteção de mulheres, jovens e crianças contra abusos, incluindo abuso sexual, exploração e violência sexuais, tráfico com fins sexuais e de meninas e mulheres, e mutilação genital e práticas correlatas.

Pela via da saúde e dos direitos reprodutivos, a questão da sexualidade começava a aparecer de uma nova maneira (CORRÊA, 2001). Nas palavras de Rosalind Petchesky (2001, p. 118-120), no Cairo, a sexualidade "começou a infiltrar-se em documentos internacionais como algo positivo, ao invés de sempre violenta, abusiva, ou santificada e escondida pelo casamento heterossexual e pela criação de crianças”. Para algumas autoras, esse passo foi fundamental para o reconhecimento posterior do direito das mulheres a terem controle sobre sua própria sexualidade (JOHNSON e TURNBULL, 1995, p. 256). Isso porque foi a "primeira vez que representantes de cerca de 180 países reconheceram que a saúde sexual era uma parte vital do bem-estar físico e psicológico de uma pessoa” (LOTTES, 2013, p. 372).

entre outros, "das crianças abandonadas, das crianças de rua, das crianças econômica e sexualmente exploradas, incluindo as que são vítimas da pornografia e prostituição infantis”.

9 Art. 12, 1. Referido artigo previa igualmente a "assistência apropriada em relação à gravidez, ao parto e ao período posterior ao parto, proporcionando assistência gratuita quando assim for necessário, e lhe assegurarão uma nutrição adequada durante a gravidez e a lactância”. A Convenção CEDAW contém, ainda, em seu art. 16, 1 dispositivos relacionados ao matrimônio, ao planejamento familiar e à parentalidade. 
À época, os principais focos de atenção dos movimentos de mulheres eram a discussão sobre o uso da expressão "direitos reprodutivos" ou "saúde reprodutiva" e a necessidade de superar o paradigma demográfico que imperava até então, segundo o qual a reprodução era examinada a partir da perspectiva do controle populacional (CORRÊA, 1997, p. 109-110). Em janeiro de 1994, em reunião preparatória no Rio de Janeiro, ter-se-ia atingido um consenso para promover as questões relacionadas à reprodução não mais sob a perspectiva meramente demográfica, mas sob a ótica da indivisibilidade dos direitos humanos e da exigência de condições econômicas, políticas e sociais que permitissem seu exercício (CORRÊA, 1997, p. 109-110). ${ }^{10}$ Para fazer valer esse ponto de vista, as feministas se aliaram a grupos de defesa do meio ambiente e do planejamento familiar interessados em manter, no documento final, itens relativos à contracepção (GIRARD, 2009, p. 169). As primeiras referências às "questões sexuais" surgiram às vésperas da conferência e foram introduzidas por delegações como a da Noruega e a da Suécia no Programa de Ação. No Cairo, feministas teriam trabalhado para incluir "direitos sexuais" no parágrafo 7.3, em que são definidos os direitos reprodutivos. Buscavam, assim, radicalizar o debate para poderem barganhar e forçar a manutenção destes últimos no texto final, como de fato veio a ocorrer (CORRÊA, 1997, p. 109-110). Nesse sentido, embora algumas questões relativas à sexualidade tenham entrado na versão final dos documentos que decorreram da Conferência do Cairo, referências a "direitos sexuais" e a "orientação sexual" presentes em minutas preliminares não foram incluídas na versão final do Programa de Ação (GIRARD, 2007, p. 319 et seq).

O grande avanço ocorrido na Conferência do Cairo, portanto, foi que a sexualidade, que aparecia no sistema ONU "apenas como algo a ser regulado em prol do interesse da ordem, da moralidade ou da saúde pública, pela primeira vez, foi reconhecida como um aspecto fundamental e positivo do desenvolvimento humano" (SAIZ, 2004, p. 50). ${ }^{11}$ Além disso, a presença no texto final do termo "direitos reprodutivos", "historicamente ligados às demandas feministas em relação ao aborto e à contracepção", representa "avanço de nomenclatura", uma vez que vai além do "termo em certa medida mais dócil”"saúde sexual” e "impõe a abertura de novas discussões em torno da sexualidade” (VIANNA e LACERDA, 2004, p. 27). Finalmente, os homens foram retratados como "corresponsáveis na problemática da reprodução” (VIANNA e LACERDA, 2004, p. 31).

10 Nesse sentido, Miriam Ventura (2002, p. 18) aponta que “[a] questão demográfica é então deslocada para o âmbito dos direitos reprodutivos e do desenvolvimento. A noção de que os direitos reprodutivos fazem parte dos direitos humanos básicos e devem orientar as políticas relacionadas à população firmam-se e avançam”.

11 O autor ressalta ainda que, no mesmo ano, foi nomeada relatoria especial sobre violência contra mulheres, "cuja análise do link entre controle da sexualidade feminina e violência contra mulheres levou, no fim das contas, a uma afirmação pioneira dos direitos das mulheres à autonomia sexual” (SAIZ, 2004, p. 50). 
Por outro lado, o processo de aprovação do documento final revela a enorme resistência aos "direitos sexuais", que sistematicamente "permaneciam entre colchetes [para serem submetidos a negociações posteriores] até serem descartados em prol do 'consenso", 12 Nota-se que as referências à sexualidade, mais uma vez, mantiveram sua ênfase voltada para os direitos das mulheres e das crianças e, embora a sexualidade tenha adquirido uma perspectiva mais positiva, continuou sendo tratada de forma limitada - vinculada à reprodução e/ou à saúde ${ }^{13}$ - e apresentada em uma chave cis-heteronormativa.

No ano seguinte, ocorreu a IV Conferência Mundial sobre a Mulher: Igualdade, Desenvolvimento, conhecida como Conferência de Beijing. Na ocasião, o Programa da Conferência avançou em termos de saúde sexual e direitos reprodutivos a partir do que havia sido estabelecido no Cairo. Foi o que ocorreu, por exemplo, em relação ao direito ao aborto. Enquanto no Cairo o aborto inseguro foi reconhecido como um problema de saúde pública (parágrafo 8.25), em Beijing recomendou-se "considerar a possibilidade de rever as leis que preveem medidas punitivas contra as mulheres que se tenham submetido a abortos ilegais”, deixando, todavia, tal tarefa a cargo dos poderes legislativos domésticos (parágrafo 106, k).

No que tange aos direitos sexuais, o parágrafo 96 da Plataforma de Ação dispôs que:

96. Os direitos humanos das mulheres incluem os seus direitos a ter controle sobre as questões relativas à sua sexualidade, inclusive sua saúde sexual e reprodutiva, e a decidir livremente a respeito dessas questões, livres de coerção, discriminação e violência. A igualdade entre mulheres e homens no tocante às relações sexuais e à reprodução, inclusive o pleno respeito à integridade da pessoa humana, exige o respeito mútuo, o consentimento e a responsabilidade comum pelo comportamento sexual e suas consequências.

Referido parágrafo é celebrado como extremamente significativo. Isso porque, mesmo diante das resistências e dos impasses entre os países, já revelados no Cairo no ano anterior, terse-ia consagrado o controle da mulher sobre a própria sexualidade, a ser exercida livre de coerção, discriminação e violência, e em igualdade em relação aos homens, além das ideias de consentimento e responsabilidade comuns (CORREAA, 1997, p. 109-110). ${ }^{14}$ Segundo Rosalind Petchesky (1995, p. 155), trata-se da “mais clara afirmação até então, em qualquer documento

12 O autor em questão refere-se especificamente à expressão "orientação sexual” (SAIZ, 2004, p. 58).

13 "7.4 A implementação do presente Programa de Ação deve ser orientada pela supramencionada definição global de saúde reprodutiva, que inclui saúde sexual.”

14 E, ainda, "A Declaração de Beijing e a Plataforma de Ação, em particular, foram grandes marcos para o reconhecimento da autonomia sexual e reprodutiva como uma base central dos direitos humanos das mulheres" (SAIZ, 2004, p. 59). 
internacional, de que mulheres - sem referência a idade, estado civil ou orientação sexual têm o direito humano à liberdade sexual".

Todavia, assim como ocorreu no Cairo, a expressão "direitos sexuais" e as referências a “orientação sexual” presentes em minutas preliminares não foram incluídas na declaração final e na Plataforma de Ação resultante da conferência (GIRARD, 2007). Um dos relevantes fatores apontados para que isso tenha ocorrido foi a resistência de países católicos e muçulmanos, articulada pela Santa Sé, à inclusão de direitos relativos à "liberdade de orientação sexual e direitos sexuais que não fossem consentâneos com os códigos sexuais familiares". ${ }^{15}$ Essa disputa entre os campos progressista e conservador não se limitava à sexualidade, mas se espraiava por debates como os concernentes ao direito ao aborto e ao uso do termo "gênero" (em oposição a "sexo”) (BUNCH e FRIED, 1996, p. 202).

Especificamente em relação ao parágrafo 96, o compromisso atingido envolvia abandonar o uso da expressão "direitos sexuais" para que seu conteúdo fosse mantido (JOHNSON e TURNBULL, 1995, p. 256). Mais uma vez, a sexualidade foi abordada de maneira limitada apenas no contexto das mulheres e meninas e "ainda implicitamente dentro da capa da saúde e dos direitos reprodutivos, ou da proteção contra violência” (MILLER e ROSEMAN, 2011b, p. 105). Além disso, ao conectar o exercício da sexualidade aos direitos reprodutivos de casais cis-heterossexuais, o referido dispositivo excluiu diversas violações de direitos experienciadas por mulheres lésbicas (MILLER, ROSGA e SATTERHWAITE, 1995, p. 437) e trans.

15 Lia Zanotta Machado (1995, p. 420-421) descreve o processo de negociação: “O famoso parágrafo 97 representava uma forma bem mais branda do que pretendera a União Europeia com a expressão mais contundente e direta de direitos sexuais das mulheres [...] A palavra sexualidade pesava. O maior temor é que incluísse direitos a liberdade de orientação sexual e direitos sexuais que não fossem consentâneos com os códigos sexuais familiares. Num esforço derradeiro foi proposta a substituição da expressão sexualidade por vida sexual [...] Por que vida sexual parecia mais palatável. Tudo indicava que sexualidade era entendida como remetendo diretamente a orientação sexual e vida sexual a heterossexualidade do casamento. [...] No último momento, no entanto, as delegações do Irã e da Argentina se pronunciaram radicalmente contrárias. Talvez tivessem percebido que afinal não haveria muita diferença entre aprovar direitos relativos a vida sexual ou direitos relativos a sexualidade. [...] Uma nova proposta no interior do grupo informal apontou em direção ao âmago de toda a Conferência: Por que não afirmar os direitos a vida sexual desde que respeitados os direitos da família? Insuficiente condição disseram uns e veio a proposta final feita e aprovada em não mais de um minuto a condição do pleno respeito das particularidades culturais. Levada ao pleno no Grupo de Trabalho sobre a Declaração, a posição da União Europeia seguida por tantos outros países progressistas foi nem pensar. Ou bem se respeitam as particularidades culturais ou bem se respeitam os direitos universais e individuais a sexualidade. No final da Conferência a Plataforma de Ação manteve o Parágrafo 97, mas mais de 40 países fizeram reservas e nenhuma menção foi feita a direitos sexuais na Declaração Política. Um século ou um milênio segundo o desejo explicitado de algumas delegações será o tempo necessário para que os países concordem em afirmar a existência de direitos sexuais para as mulheres". 
Especificamente em relação às mulheres lésbicas, registra-se sua intensa mobilização à época da conferência, o que levou à inclusão, em documentos preparatórios, de cinco parágrafos contendo expressões como “orientação sexual", "direitos sexuais" e "autonomia sexual”, todas entre colchetes e todas posteriormente descartadas (WILSON, 1996, p. 216-217).

Como visto ao longo deste item, na trajetória das conferências dos anos 1990 sobre direitos das mulheres houve um progressivo avanço no tratamento da sexualidade, evidenciandose, a cada etapa, limites e tensões. Em Viena, em prol da proteção de mulheres e crianças, abusos e violências de cunho sexual, incluindo o estupro, passaram a ser vistos como violações de direitos humanos. Entretanto, a sexualidade continuava sendo abordada apenas de maneira negativa, sob a perspectiva da necessidade de proteção contra o abuso e a violência. No Cairo, por sua vez, a sexualidade passou a ser tratada, sob a ótica da saúde sexual, de maneira mais positiva, como fator fundamental para o desenvolvimento do ser humano (e não como mero instrumento a serviço da coletividade, superando-se o paradigma demográfico). Finalmente, em Beijing ocorreu a afirmação mais explícita da liberdade sexual das mulheres.

Apesar da evolução verificada nas sucessivas conferências, o tratamento da sexualidade permaneceu vinculado à saúde e/ou atrelado aos direitos reprodutivos de casais cis-heterossexuais, e em nenhum dos documentos finais das conferências mencionadas foram mantidas as referências a "orientação sexual”, “direitos sexuais" e “autonomia sexual”. Em outras palavras, a viabilização dos avanços no campo da saúde sexual e dos direitos reprodutivos ocorreu à custa da domesticação da ideia de sexualidade, em que aspectos considerados mais controversos foram utilizados como moeda de troca durante as barganhas políticas ocorridas nas conferências até serem, finalmente, excluídos.

Em suma, superadas algumas das contradições iniciais presentes na discussão jurídica sobre sexualidade na esfera internacional (em especial a visão demográfica e/ou negativa da sexualidade), outros limites se mantiveram nos documentos finais produzidos nas conferências ocorridas nos anos de 1990 (como o atrelamento às ideias de saúde e reprodução e a exclusão de manifestações tidas como desviantes, notadamente por meio da retirada das expressões “orientação sexual” e “autonomia sexual”).

\section{I.4. ANOS 2000 E ALÉM: AVANÇOS E OBSTÁCULOS}

Nos anos que se seguiram, o avanço dessas pautas foi prejudicado por uma série de fatores. Segundo Françoise Girard (2009, p. 171-172), nas reuniões de revisão após cinco anos das conferências originais (ICPD+5, em 1999, e Beijing +5, em 2000), foram verificadas a consolidação da aliança conservadora já iniciada entre Vaticano e países muçulmanos, a ascensão do conservadorismo nos Estados Unidos, a presença de diplomatas profissionais em vez de especialistas em saúde (como havia ocorrido nas conferências originais) e a decisão dos países em desenvolvimento (G-77) de manifestarem voto único como forma de obter avanços em pautas de justiça econômica (não obstante manifestações individuais de países latino-americanos como Brasil e Peru, que formaram uma frente progressista). 
Dez anos após as conferências originais, em razão do clima político conservador liderado pelo governo de George W. Bush nos Estados Unidos, ativistas de direitos e saúde das mulheres, assim como governos progressistas, opuseram-se à realização de conferências globais de revisão temendo reabrir os debates e acarretar mais perdas do que ganhos (GIRARD, 2009, p. 173). Nesse contexto, em 2004 o Brasil propôs adiar discussão na Comissão de Direitos Humanos da ONU sobre resolução relativa à orientação sexual que havia encaminhado no ano anterior em razão da forte oposição de governos que argumentavam "não se tratar de assunto apropriado para a consideração de um órgão de direitos humanos” (SAIZ, 2004, p. 50).

Apesar dos avanços do conservadorismo, comentadores chamam atenção para o fato de que a "participação e a visibilidade" de grupos pró-reconhecimento de direitos relativos à orientação sexual aumentaram ao longo dos anos 2000, assim como o número de países e instituições de direitos humanos que passaram a encampar essa agenda (SAIZ, 2004, p. 59). Nesse cenário, foram editadas, pela sociedade civil, as declarações mencionadas no item 1.1 (Princípios deYogyakarta, Declaração sobre Direitos Sexuais da World Association for Sexual Health, Declaração sobre Direitos Sexuais da International Planned Parenthood Federation e outras). Contudo, tanto essas declarações, oriundas de entidades e articulações não governamentais, quanto os documentos resultantes das Conferências de Viena, Beijing e do Cairo, que são declarações políticas, não são juridicamente vinculantes para os Estados.

Até hoje não existe um tratado de direitos humanos que trate especificamente de direitos sexuais, embora, como visto, haja em diversos tratados internacionais dispositivos esparsos que abordam temas relativos à sexualidade. Esse fato reflete a ideia de que a "consolidação da problemática dos direitos sexuais tenha passado, em termos de encontros internacionais, pelas temáticas da população ou da mulher, não se constituindo como um campo específico de regulação, mas sendo incluído em áreas já legitimadas" (VIANNA e LACERDA, 2004, p. 25).

Como visto, o atrelamento dos direitos sexuais a outras pautas contribuiu para que certos aspectos da sexualidade fossem obliterados ou desfavorecidos no âmbito do debate internacional. Nesse sentido, o alcance dos “direitos sexuais" se viu em disputa, sendo utilizados para promover dois diferentes grupos de direitos, que obtiveram, ao longo do tempo, graus de avanço distintos na esfera internacional. De um lado, direitos relativos a acesso a serviços de saúde relacionados à sexualidade e à reprodução, incluindo planejamento familiar, informação e educação. De outro, direitos relativos à orientação sexual e à identidade de gênero.

Enquanto movimentos de mulheres promoviam o primeiro conjunto de direitos, o segundo foi trazido ao debate público por ativistas no campo do HIV / AIDS, de início preocupados com homens que têm relações sexuais com homens e direitos de pessoas gays. ${ }^{16}$ 
Em diversos momentos, tais grupos disputaram não só prioridades e estratégias, mas também financiamento e credibilidade. ${ }^{17}$ Para alguns comentadores, organizações tradicionais de direitos humanos temiam o envolvimento com temas que pudessem gerar "risco social ou governamental", como reações homofóbicas de seus próprios membros ou perda de status perante governos (ROTHSCHILD, 2004, p. 166). Para outros, além da LGBTfobia, outros fatores concernentes a "uma certa bagagem ideológica" teriam contribuído para a supressão de temas relacionados à sexualidade por parte de atores mais tradicionais no contexto dos direitos humanos. ${ }^{18}$

Esses debates, em especial nas Nações Unidas, "ergueram uma linha de Maginot política entre 'sexual' e 'reprodutivo' e entre 'saúde' e 'direitos' como parâmetro de legitimidade" (MILLER e ROSEMAN, 2011a, p. 333). Na polarização, "saúde" e "reprodutivo" estariam de um lado, e "direito” e “sexual”, de outro. Os primeiros denotariam “'bom comportamento” e [seriam] vistos como conceitos aceitáveis por instituições” (CORRÊA, 1997, p. 110), muitas vezes limitados ao entendimento tradicional relacionado à saúde materna e infantil e ao planejamento familiar. Já os segundos seriam enxergados como mais radicais, o que os levaria a serem “minimizados ou excluídos no desenho ou aplicação de políticas públicas” (CORREAA, 1997, p. 110). Mesmo a ênfase na saúde sexual (como uma tentativa de meio-termo) é criticada por encerrar um risco de que a visão do sexo como uma prática "saudável” possa descambar

17 Marge Berer (2011, p. 6-7) aponta, entre outros fatores que contribuem para essa divisão, "que as iniciativas verticais de saúde global (financiamento), que agora representam a maior parte do financiamento para a saúde global, excluem a atenção às doenças sexuais e reprodutivas (com exceção do HIV/AIDS, que é muito bem financiado, e saúde materna, neonatal e infantil, em que a grande maioria do financiamento não é para mulheres); que os órgãos de direitos humanos estão muito afobados para promover e defender o direito ao aborto, mesmo que agora se sintam capazes de apoiar certos equipamentos sexuais; que abusos de saúde e direitos sexuais e reprodutivos podem ser uma causa e/ou consequência de outros abusos de direitos humanos e, ainda assim, são raramente mencionados em outras lutas pelos direitos humanos; que, embora a importância global do papel dos profissionais de saúde, especialmente em relação ao HIV, à necessidade de um papel estatal forte e à centralidade da participação destes profissionais nos debates sobre políticas tenham sido acordados na $53^{\text {a }}$ sessão da Comissão sobre a Situação da Mulher (CSW), o quadro de atuação dos profissionais de saúde também restringiu o debate, particularmente sobre os direitos das pessoas com deficiência e as variações na formação da família, devido à participação de ONGs conservadoras; e que o ressurgimento da oposição aos direitos sexuais e reprodutivos, encabeçado pelo Vaticano, conspira paralelamente, competindo as prioridades para afastar grande parte do trabalho em nosso campo, apesar de quanto ainda resta a ser realizado”.

18 " [...] o legado da esquerda; os preconceitos econômicos e as desconfianças do individualismo burguês; o legado do nacionalismo e a desconfiança do imperialismo cultural do Ocidente; o legado pós-modernista de Foucault, que tanto 'descobriu' como registrou o 'eu' sexual como uma ilusão do Iluminismo europeu” (PETCHESKY, 1999, p. 33). 
tanto para a "medicalização de todos os aspectos da sexualidade" quanto para a exclusão de práticas que sejam consideradas "não saudáveis" ou "pervertidas" (MILLER, 2000, p. 70).

Nesse contexto, a fusão entre direitos reprodutivos e sexuais teria feito com que os segundos passassem a ser vistos como uma categoria subordinada e condicionada aos primeiros, o que faz com que certas práticas sexuais não procriativas e/ou não cis-heterossexuais estejam fora do seu âmbito de proteção, sendo relegadas "à regulação moral, religiosa ou criminal” (MILLER, 2000, p. 70). Além disso, a associação com os direitos reprodutivos faz com que toda uma miríade de pessoas não seja enxergada como sujeitos de direitos sexuais, como pessoas de certa idade (idosos, por exemplo), pessoas de identidades de gênero não conforme e, frequentemente, homens (MILLER, 2000, p. 70).

Em síntese, as contradições observadas no tratamento dos direitos sexuais durante as conferências internacionais dos anos 1990 refletiram-se na fragmentação das abordagens sobre sexualidade e identidade de gênero nos anos 2000, em franca contrariedade às ideias de indivisibilidade, inter-relação e interdependência dos direitos humanos. Nesse processo, os direitos sexuais passaram a ser vistos como uma categoria subordinada e condicionada aos direitos reprodutivos, o que contribuiu para marginalizar certas práticas, identidades e agendas não hegemônicas.

\section{OS DIREITOS SEXUAIS NO BRASIL}

\section{I. DEBATE SOBRE OS DIREITOS SEXUAIS NO BRASIL}

A discussão sobre direitos sexuais adentra o debate brasileiro a partir da literatura especializada. Neste item, serão apontadas obras que pioneiramente se debruçaram sobre os "direitos sexuais”, contribuindo para a construção do campo e de seu significado. ${ }^{19}$

A partir da década de 1970, "com a emergência dos movimentos feminista e homossexual, além do interesse pelo tema por parte de organismos e agências internacionais, as Ciências Sociais voltaram o olhar para as temáticas da mulher e da sexualidade” (CITELI, 2005, p. 17). O uso da expressão "direitos sexuais" no Brasil, porém, remonta à segunda metade da década de 1990 e dialoga com o debate que vinha ocorrendo no âmbito internacional. Em artigo de 1995 sobre o tema, Lia Zanotta Machado discute resultados e limites da IV Conferência sobre

19 Pesquisa realizada pela expressão exata "direitos sexuais" na biblioteca do Senado Federal. Disponível em: https: / /www12.senado.leg.br/institucional/biblioteca. Acesso em: 20 dez. 2018. A única entrada anterior é artigo de jornal de 1987 intitulado "Direitos sexuais têm apoio de 47 constituintes". Folha de São Paulo, 9 de junho de 1987. Em pesquisa realizada no portal de periódicos da Capes, as primeiras entradas referem-se à edição da revista Estudos Feministas e seus respectivos artigos aqui mencionados. 
a Mulher em Beijing e vincula a perspectiva de gênero ao reconhecimento da liberdade sexual de homens e mulheres. ${ }^{20} \mathrm{Na}$ mesma edição da revista Estudos Feministas, a expressão é também utilizada por Maria Luiza Heilborn e Maria Aparecida Schumaher, ambas em alusão à referida conferência, indicando que o uso da expressão "direitos sexuais" no Brasil se deu a partir do debate ocorrido naquele contexto.

No ano seguinte, Maria Betânia Ávila e Taciana Gouveia (1996, p. 165) procuraram diferenciar direitos reprodutivos e sexuais, afirmando serem os segundos "uma temática nova" que, "de modo geral, nas formulações feministas vêm comumente atrelados à saúde e aos direitos reprodutivos". Em seu trabalho, as autoras alertam, contudo, que a junção desses direitos pode ir na contramão dos esforços dos movimentos feministas ao limitar a sexualidade da mulher às ideias de maternidade e reprodução. Nesse sentido, chamam atenção para a tensão que existe entre gênero e sexualidade. Por um lado, afirmam que, em nossa sociedade, a vivência sexual se constrói a partir das relações de gênero e, ao mesmo tempo, o "tornar-se homem ou mulher" ainda está atrelado à vivência sexual. Por outro, sinalizam que essa ideia de sexualidade é "excludente", uma sexualidade "reduzida", limitada a "um casal formado por um homem e uma mulher, casados, monogâmicos e que mantêm a estrutura ativo/passivo, não só no ato em si como também na vida cotidiana" (ÁVILA e GOUVEIA, 1996, p. 167). E chamam atenção para o fato de que a intensa regulação da sexualidade convive com o fato de ser "o lugar por excelência da transgressão". 21

Em 2001, edição do Jornal da RedeSaúde "é dedicada ao debate sobre os direitos sexuais como uma questão de direitos humanos, que vem apresentando novos desafios ao movimento de mulheres na definição de sua pauta e de suas estratégias de advocacy”. A edição conta com onze contribuições que abarcam "leque amplo de discussões sobre os direitos sexuais, que incluem, além dos direitos de gays e lésbicas e dos/as heterossexuais, outros temas polêmicos e atuais, como a violência sexual, a mutilação genital e a prostituição forçada” (JORNAL DA REDESAÚDE, 2001).

Embora a apresentação da edição anteriormente reproduzida defina "direitos sexuais" de maneira ampla, abrangendo pautas feministas e LGBTs, o artigo que a apresenta e introduz,

20 Veja-se: “Aí entra-se direta e frontalmente no entendimento da noção de direitos sexuais e no confronto entre direitos familiares e direitos individuais e entre o respeito à diversidade cultural e o respeito aos direitos individuais. A perspectiva de gênero vista pelo lugar do conflito político do conceito parece estar assim estreitamente vinculada à ideia de liberdade de opção sexual e à ideia de que homens e mulheres são iguais para optarem por diferentes formas de viver sua sexualidade” (MACHADO, 1995, p. 419).

21 No mesmo ano, Sonia Corrêa e Rosalind Petchesky (1996) trataram de questões relativas à sexualidade, como "o prazer sexual e o direito de expressá-lo de formas diversificadas e não estigmatizadas", sob a expressão “direitos sexuais e reprodutivos”, sem, contudo, diferenciar explicitamente seu conteúdo. 
de autoria de Gilberta Santos Soares (2001, p. 5), revela que a associação entre essas pautas não é automática nem livre de tensões:

Reconhecer que o feminismo, em sua contemporaneidade, apresenta um conjunto de afinidades com o movimento de defesa dos direitos de lésbicas e gays e que ambos despontam como movimentos sociais que têm contribuído decisivamente para a mudança de costumes e valores na sociedade brasileira implica a necessidade de assumir o desafio de favorecer o diálogo, a confrontação e a proximidade das ações, teorias e análises feministas e homossexuais. Para tanto, faz-se necessário reconhecer que a clandestinidade do lesbianismo, pouco estudado e ainda carente de visibilidade social, reproduziu-se no interior do feminismo, produzindo um vácuo e o distanciamento das ações das ativistas lésbicas e feministas, assim como deixando internamente uma lacuna na abordagem dos direitos das mulheres lésbicas.

Para além da tensão política entre movimentos, a autora chama atenção para o fato de que, não obstante ter o feminismo sempre tido "a sexualidade e a liberdade sexual como um princípio fundamental de luta [...], essa discussão esteve prioritariamente articulada ao campo reprodutivo e a construção teórica e política da escolha da sexualidade como direito deu-se no marco da vivência heterossexual, ainda que a liberdade de escolha sexual tenha estado presente no campo da vida privada de muitas mulheres feministas" (SOARES, 2001, p. 5).

Nesse ponto, é importante notar que Gilberta Santos Soares, na afirmação transcrita, conecta a dimensão da disputa política em torno dos direitos sexuais com a dimensão teórica relacionada aos debates dentro do próprio feminismo, conclamando uma leitura mais ampla e inclusiva. Nesse sentido, relatório de 2004 produzido pelo Centro Latino-Americano em Sexualidade e Direitos Humanos (CLAM), vinculado ao Instituto de Medicina Social da Universidade do Estado do Rio de Janeiro (UERJ), intitulado "Direitos e políticas sexuais no Brasil: o panorama atual", abarca temas como "orientação sexual, prostituição, violência sexual, censura e pornografia, saúde reprodutiva e aborto, DST/AIDS” (VIANNA e LACERDA, 2004, p. 11). Além de ampliar o rol das temáticas abrangidas pelo debate acerca de direitos sexuais, buscando articular feminismo e pautas LGBT, referido relatório faz menção a diplomas internacionais, mas tem seu foco voltado para a legislação brasileira concernente a esses temas.

Já no contexto da literatura jurídica nacional, Roger Raupp Rios (2007) incorpora essa abertura dos direitos sexuais ao propor a construção de um "direito democrático da sexualidade" e chama atenção para a necessidade de princípios capazes de abarcar "questões identitárias vinculadas à expressão da sexualidade (onde se inserem, principalmente, os temas das homossexualidades), as relações homossexuais propriamente ditas e suas consequências (campo que alcança matérias diversas como consentimento, violência e aborto) e a busca da 
fundamentação dos direitos sexuais (historicamente atada à ideia de saúde sexual)" (RIOS, 2006, p. 73). Em uma perspectiva normativa, o autor propõe a complementação dos "direitos sexuais", ancorados nas ideias de liberdade, igualdade e dignidade com um elemento democrático visando a assegurar a "participação dos beneficiários e destinatários das políticas públicas a serem desenvolvidas" por um "direito democrático da sexualidade" (RIOS, 2006, p. 84). Laura Davis Mattar (2008, p. 65), por sua vez, busca diferenciar direitos sexuais e reprodutivos a partir de sua trajetória histórica, enfatizando que a dificuldade ainda hoje observada de se "separar a prática do sexo da finalidade da reprodução", entre outras razões, teria contribuído para que a formulação e o reconhecimento jurídico dos direitos reprodutivos estivessem mais desenvolvidos que a dos direitos sexuais.

Como se vê, desde o início dos debates sobre o assunto no Brasil, houve preocupação em discutir o conceito de direitos sexuais de uma maneira crítica, propondo uma abordagem inclusiva e apontando para os riscos de limitar os direitos sexuais à saúde e à reprodução, em uma chave cis-heterossexual que apagasse, por exemplo, as pautas trans e homossexuais. No próximo item, verificaremos que isso não necessariamente se refletiu nos usos jurídico e político do conceito de direitos sexuais pelas instâncias governamentais no Brasil, que, por um lado, pouco adotaram a noção e, por outro, quando o fizeram, restringiramse aos temas da saúde, particularmente reprodutiva, e aos direitos das mulheres, sobretudo no que concerne à violência.

\subsection{USO DA EXPRESSÃO “DIREITOS SEXUAIS" NO ÂMBITO ESTATAL NO BRASIL}

A Constituição brasileira, como quase todas as constituições em vigor, ${ }^{22}$ não contém a expressão "direitos sexuais". No que tange à temática da sexualidade, embora o debate jurídico sobre

22 A exceção é a Constituição da Bolívia de 2009, que em seu art. 66 dispõe acerca da garantia a "mulheres e homens [d]o exercício de seus direitos sexuais e seus direitos reprodutivos". Além de assegurar direitos sexuais e reprodutivos a homens e mulheres, referida constituição veda a discriminação por orientação sexual e garante a todas as pessoas o direito à "integridade sexual”. Além dessas cláusulas gerais, assegura o direito de todos, em especial mulheres, de não sofrerem violência sexual, e dispõe sobre a obrigação do Estado de "prevenir, eliminar e punir" violência sexual ou sofrimento sexual na família bem como na sociedade. Ainda no contexto sul-americano, a Constituição do Equador se destaca por sua abrangência e detalhamento no tratamento da sexualidade, ainda que não empregue a expressão "direitos sexuais". Aprovada por referendo popular em 2008, a Constituição equatoriana veda a discriminação por orientação sexual e HIV (art. 11) e estabelece o dever de todos os cidadãos de respeitar e reconhecer diferenças de gênero, orientação sexual e identidade (art. 83). Estabelece, igualmente, o dever do Estado de promover a saúde reprodutiva e sexual (art. 32) e em especial das mulheres, principalmente durante a gravidez, o parto e o pós-parto (art. 363). Prevê, ainda, a prioridade de acesso a serviços públicos e privados a pessoas vítimas de violência doméstica e sexual (art. 35); o dever do Estado de proteção contra exploração sexual de crianças e adolescentes (art. 46); o dever do Estado de salvaguardar a integridade corporal, psicológica e sexual dos estudantes (art. 347); a exceção ao privilégio de não testemunhar contra parentes e 
o tema tenha se dado de maneira ampla durante a Assembleia Constituinte de 1987-1988, ${ }^{\mathbf{2 3}}$ o texto final da Constituição limitou-se a estabelecer a punição à violência sexual contra criança e adolescente. ${ }^{24}$ Previu, ainda, o livre planejamento familiar como um direito do casal. ${ }^{25}$ Como se vê, o texto constitucional de 1988 é marcado, de um lado, por uma dimensão protetiva da sexualidade, que busca assegurar a proteção estatal de mulheres e crianças contra violação de direitos decorrentes do uso violento ou abusivo da sexualidade, e, de outro, por uma dimensão reprodutiva, refletida na ideia de livre planejamento familiar. Aspectos como a vedação de discriminação por orientação sexual, embora tenham sido objeto de debate, foram deliberadamente deixados de fora do texto final. ${ }^{26}$

Embora o Estado brasileiro viesse lidando com questões relativas à sexualidade nas décadas anteriores, inclusive por meio de programas como o Programa de Combate à AIDS, iniciado na década de 1980 (GALVÃO, 2000), a expressão “direitos sexuais" começa a ser utilizada nesse âmbito apenas a partir dos anos 2000 e seu uso mantém-se de certa maneira esporádico, sem necessariamente incorporar os debates trazidos pela literatura especializada nacional e estrangeira.

$\mathrm{Na}$ esfera do Executivo federal, seu emprego se dá por meio da expressão "direitos sexuais e reprodutivos", uso que é mantido ao longo dos anos nos três documentos em que foi encontrada (um de 2003, um de 2005 e um de 2017). ${ }^{27}$ Paralelamente, o Ministério da

companheira(o) em caso de violência sexual, doméstica e de gênero (art. 77); e a existência de procedimentos especiais para julgar e punir crimes sexuais (art. 81). Por fim, o art. 66, que é o primeiro artigo do capítulo dos "Direitos de Liberdade", estabelece o direito à integridade sexual como parte da integridade pessoal, o direito de tomar decisões "livres, informadas, voluntárias e responsáveis" sobre sexualidade e orientação sexual, e o direito de guardar reserva sobre informações sobre a vida sexual individual.

23 Veja-se, por exemplo, a carta das mulheres encaminhada pelo Conselho Nacional dos Direitos da Mulher aos constituintes. Disponível em: http://www2.camara.leg.br/atividade-legislativa/legislacao/Constituicoes_Brasileiras/constituicao-cidada/a-constituinte-e-as-mulheres/arquivos / Constituinte\%2019871988-Carta\%20das\%20Mulheres\%20aos\%20Constituintes.pdf. Acesso em: 3 abr. 2020.

24 Art. 227, $\S 4^{\circ}$ : "A lei punirá severamente o abuso, a violência e a exploração sexual da criança e do adolescente".

25 Art. 226, § $7^{\circ}$ : "Fundado nos princípios da dignidade da pessoa humana e da paternidade responsável, o planejamento familiar é livre decisão do casal, competindo ao Estado propiciar recursos educacionais e científicos para o exercício desse direito, vedada qualquer forma coercitiva por parte de instituições oficiais ou privadas”.

26 Embora a articulação visando a incluir a discriminação por orientação sexual tenha sido derrotada naquela ocasião e posteriormente no processo de revisão constitucional, a demanda foi contemplada nas Constituições Estaduais e nas leis orgânicas municipais (RIOS, 2001). Posteriormente, Piauí e Distrito Federal. Sobre o tema, cf. Rios (2001).

27 Decreto não numerado de 27 de agosto de 2003 instituiu "Grupo de Trabalho Interministerial com a finalidade de promover o debate nacional sobre os direitos sexuais e direitos reprodutivos, com ênfase na paternidade 
Saúde, a partir de 2005, também passa a utilizar a expressão associada à ideia de planejamento familiar com ênfase em direitos de mulheres e adolescentes. ${ }^{\mathbf{2 8}}$

A partir de 2009, contudo, o Ministério da Saúde passa a adotar uma definição de direitos sexuais mais ampla, com um conteúdo próprio e que abarca diferentes aspectos da sexualidade. Veja-se: "[o] Direito de viver e expressar livremente a sexualidade sem violência, discriminações e imposições”, "[o] Direito de viver plenamente a sexualidade sem medo, vergonha, culpa e falsas crenças”, “[o] Direito de viver a sexualidade independentemente de estado civil, idade ou condição física”, “[o] Direito de ter relação sexual independente da reprodução”, “[o] Direito ao sexo seguro para prevenção da gravidez indesejada e de DST/HIV / AIDS”, e "[o] Direito a serviços de saúde que garantam privacidade, sigilo e atendimento de qualidade e sem discriminação" (BRASIL, 2009, p. 4).

Em documentos posteriores, o órgão expande essa definição, fundamentando os direitos sexuais na Constituição Federal, diferenciando-os explicitamente dos direitos reprodutivos e chamando atenção para os diferentes sujeitos e grupos que "têm seus direitos humanos infringidos em função da sexualidade" e para os quais "se acha que a reprodução não deve acontecer":

Assim, entre os direitos considerados fundamentais para o exercício da cidadania e inerentes à condição de pessoa que vive em sociedade, estão os Direitos Humanos, preconizados pela Constituição Federativa do Brasil de 1988, que são: o direito à vida, à alimentação, à saúde, à moradia, à educação, ao afeto e aos direitos sexuais e aos direitos reprodutivos. [...]

consciente e atuante, visando garantir o efetivo acesso ao planejamento familiar para homens e mulheres" (art. $1^{\circ}$ ). O segundo, Decreto n. 5.390, de 8 de março de 2005, entre outras providências, aprovou o Plano Nacional de Políticas para as Mulheres (PNPM), que continha, entre seus objetivos, "Garantir os direitos sexuais e direitos reprodutivos das mulheres" (Anexo - item 3.2). Referido dispositivo foi mantido em sua literalidade pelo Decreto n. 6.387, de 5 de março de 2008 (II Plano Nacional de Políticas para as Mulheres), que o substituiu até ser definitivamente revogado pelo Decreto n. 7.959, de 13 de março de 2013. Por fim, o Decreto n. 9.223/2017, que institui a Rede Brasil Mulheres, trouxe como um de seus objetivos "promover a melhoria das condições de vida e de saúde das mulheres em todas as fases da vida e garantir os direitos sexuais e reprodutivos" (art. $3^{\circ}$, II). Os dois primeiros documentos foram encontrados em busca realizada no Portal da Legislação, "base de dados que reúne atos de hierarquia superior, da legislação federal brasileira, cuja área de abrangência vai desde a proclamação da República em 1889 até hoje, sendo constantemente atualizada e mantida pela Subchefia para Assuntos Jurídicos da Casa Civil da Presidência da República”. Disponível em: https: / legislacao.planalto.gov.br/. Acesso em: ago. 2018. Os demais aparecem somente na busca da Câmara dos Deputados, que, por sua vez, não revela os dois primeiros. Disponível em: http: / / www2.camara.leg.br/atividade-legislativa/legislacao. Acesso em: ago. 2018.

28 O primeiro documento encontrado, "Direitos sexuais e direitos reprodutivos: uma prioridade do governo" (BRASIL, 2005), pretende "garantir os direitos de homens e mulheres, adultos(as) e adolescentes, em relação 
Diferentes grupos têm seus direitos humanos infringidos em função da sexualidade, tais como lésbicas, gays, bissexuais, travestis e transexuais, bem como profissionais do sexo e pessoas que vivem com HIV/aids. Para outros grupos não é reconhecido o direito do exercício da sexualidade, como no caso das pessoas idosas e das pessoas com deficiência. Ainda há outros segmentos para os quais se acha que a reprodução não deve acontecer, como no caso das pessoas com deficiência, em situação de prisão, adolescentes e pessoas com orientações sexuais não heterossexuais. É fundamental, para que uma sociedade seja justa e equitativa, que sejam assegurados os direitos humanos, respeitando-se e aceitando-se as diferenças humanas. (BRASIL, 2017, p. 138-140)

O uso muito rarefeito e sem grande relevância do termo no âmbito do Executivo mais geral contrasta, portanto, com sua presença e seu desenvolvimento no âmbito do Ministério da Saúde. Nessa esfera, em um primeiro momento, o termo aparece de maneira indefinida e indiferenciada na expressão mais ampla "direitos sexuais e reprodutivos", associado à ideia de planejamento familiar com ênfase nos direitos de mulheres e adolescentes. Posteriormente, os "direitos sexuais" adquirem um conteúdo próprio que abarca diferentes aspectos de sexualidade e identidade de gênero. Ainda assim, seu uso, na esfera do Executivo federal, permanece adstrito ao campo da saúde.

No âmbito do Poder Legislativo federal, na Câmara dos Deputados, dos projetos de lei encontrados contendo a expressão "direitos sexuais", três deles tratam de exploração sexual de crianças e adolescentes, ${ }^{29}$ cinco deles de violência contra a mulher, ${ }^{30}$ seis deles abordam direitos reprodutivos das mulheres, ${ }^{31}$ um institui a semana nacional de atenção à saúde do

à saúde sexual e à saúde reprodutiva, enfocando, principalmente, o planejamento familiar”, e baseia-se no dispositivo constitucional que prevê "a responsabilidade do Estado no que se refere ao planejamento familiar" (art. 226, $\S 7^{\circ}$ ), na Lei n. 9.263/1996, que regulamenta o planejamento familiar no Brasil, e, no âmbito internacional, nos Programas e Plataformas de Ação propostos na Conferência Internacional da ONU sobre População e Desenvolvimento (CIPD), realizada no Cairo, em 1994, e na IV Conferência Mundial sobre a Mulher, realizada em Pequim, em 1995.

29 PLs n. 6.938/2010 e 3.868/2015: dispõem sobre a reparação civil coletiva decorrente da exploração sexual de crianças e adolescentes para fins comerciais e dá outras disposições protetivas dos direitos das crianças e dos adolescentes; e PL n. 10.613/2018: institui a semana nacional de prevenção do abuso e da exploração sexual de crianças e adolescentes.

30 PLs n. 7.659/2010, 2.366/2011, 235/2011, 258/201: alteram o Código de Processo Penal para estabelecer prioridade na realização de exames periciais quando a vítima for mulher, especialmente nos casos de violência doméstica e familiar; e PL n. 9.559/2018: altera o Código para tipificar o crime de violência psicológica contra a mulher.

31 PL n. 1.686/2007: altera a lei de planejamento familiar para incluir os métodos naturais de concepção e contracepção; PL n. 2.690/2007: altera o Código para tipificar como crime a propaganda e o induzimento 
homem ${ }^{32}$ um deles cria o Dia Nacional da Visibilidade Lésbica (PL n. 2.000/2007) e o outro (PL n. 4.828/2016) busca a promoção do Pacto Federativo de Igualdade entre Homens e Mulheres, que inclui "garantir o direito à proteção da saúde, incentivando a revisão de protocolos de acordo a fim de que seja respeitada a diversidade sexual e, conferir especial atenção aos direitos sexuais e reprodutivos, principalmente nos locais de baixo IDH" (art. 10, VI). Finalmente, o PL n. 882/2015, em tramitação, estabelece políticas públicas no âmbito da saúde sexual e dos direitos reprodutivos, incluindo autorização para realização do aborto até doze semanas de gravidez. ${ }^{33}$

No Senado Federal, ${ }^{34}$ encontra-se o uso da expressão apenas em dois pedidos de realização de audiência pública, um para debater a aplicação da Lei n. 9.797/1999, que dispõe sobre

aos métodos ou substâncias abortivas; PL n. 5.069/2013: altera o Código Penal para tipificar como crime contra a vida o anúncio de meio abortivo e prevê penas específicas para quem induz a gestante à prática de aborto; PL n. 7.633/2014: dispõe sobre a humanização da assistência à mulher e ao neonato durante o ciclo gravídico-puerperal e dá outras providências; e PL n. 3.901/2015: altera a Lei do SUS para ampliar sua atuação na saúde integral da mulher.

32 PL n. 6.011/2016: institui a Semana nacional de atenção à saúde do homem. "A programação da Semana incluirá atividades educativas que visem à prevenção de doenças, à promoção da saúde e à conscientização sanitária, sendo abordados os agravos mais frequentes na população masculina de cada localidade, como doenças cardiovasculares, hipertensão arterial, diabetes, doenças do aparelho geniturinário e da próstata, neoplasias, andropausa, impotência, infertilidade, direitos sexuais e reprodutivos, doenças sexualmente transmissíveis, saúde mental, além de outras doenças e situações que afetem a saúde e o bem-estar da população masculina” (art. $\left.1^{\circ}, \S 1^{\circ}\right)$.

“Art. $3^{\circ} \mathrm{O}$ Estado garantirá o direito à reprodução consciente e responsável, reconhecendo o valor social da maternidade na garantia da vida humana, e promoverá o exercício pleno dos direitos sexuais e reprodutivos de toda a população, entendendo-se que a interrupção voluntária da gravidez não constitui um instrumento de controle de natalidade."

"Art. $7^{\circ} \mathrm{O}$ poder público, no desenvolvimento de suas políticas de saúde e sociais, garantirá: I - A informação e educação sexual e reprodutiva nos conteúdos formais do sistema de educação. II - O acesso universal aos serviços e programas de saúde sexual e reprodutiva. III - A informação sobre contracepção e sexo seguro que previna tanto as Doenças Sexualmente Transmissíveis (DST-HIV) quanto a gravidez não desejada. IV - O acesso a métodos seguros de contracepção de emergência em todas as unidades da rede pública de saúde e o acesso às informações corretas de sua utilização. V - O aumento da oferta e diversidade de métodos contraceptivos nos serviços públicos de saúde, de modo a assegurar a todas as mulheres, do campo, da floresta e das cidades, durante toda a sua vida fértil, da puberdade à menopausa, o acesso a métodos seguros e saudáveis de evitar filhos, escolhidos de maneira correta e adequada às dinâmicas e peculiaridades de sua vida. VI - Ações informativas e de sensibilização sobre saúde sexual e saúde reprodutiva, especialmente através dos meios de comunicação.”

34 Pesquisa textual (Ementa/explicação da ementa/indexação/apelido): "direitos sexuais", em tramitação ou com tramitação encerrada. Disponível em: https://www25. senado.leg.br/web/atividade/materias. Acesso em: 20 fev. 2018. 
a obrigatoriedade da cirurgia plástica reparadora de mama pela rede de unidades integrantes do Sistema Único de Saúde (SUS) nos casos de mutilação decorrentes de tratamento de câncer (SF RAS 70/2011), e outro para debater o fenômeno da discriminação de gênero no sistema penal (SF RVM 23/2016), ambos propostos pela senadora Vanessa Grazziotin.

Como se nota, uma grande parte dos projetos de lei volta-se para temas relacionados à saúde, outra parcela significativa aborda direitos reprodutivos das mulheres, e boa parte destes se localiza na interseção entre os dois temas. Interessante notar que, diferentemente do observado no âmbito do Ministério da Saúde, a ênfase dos projetos de lei recai sobre a dimensão negativa dos direitos sexuais. Isto é, tratam não da promoção de determinados aspectos da sexualidade, mas da proteção contra o abuso sexual de crianças e adolescentes e da violência contra a mulher. A exceção é o projeto de lei na Câmara que propõe a criação do Dia Nacional da Visibilidade Lésbica.

Das leis aprovadas, três mencionam “direitos sexuais”. A primeira, Lei n. 11.340/2006 (Lei Maria da Penha), inclui a expressão na definição de violência sexual,

entendida como qualquer conduta que a constranja a presenciar, a manter ou a participar de relação sexual não desejada, mediante intimidação, ameaça, coação ou uso da força; que a induza a comercializar ou a utilizar, de qualquer modo, a sua sexualidade, que a impeça de usar qualquer método contraceptivo ou que a force ao matrimônio, à gravidez, ao aborto ou à prostituição, mediante coação, chantagem, suborno ou manipulação; ou que limite ou anule o exercício de seus direitos sexuais e reprodutivos. (art. $7^{\circ}$, III)

A Lei n. 12.852/2013, Estatuto da Juventude, por sua vez, estabelece como uma das diretrizes para política pública de atenção à saúde do jovem a "garantia da inclusão de temas relativos ao consumo de álcool, tabaco e outras drogas, à saúde sexual e reprodutiva, com enfoque de gênero e dos direitos sexuais e reprodutivos nos projetos pedagógicos dos diversos níveis de ensino" (art. 20, IV). Nota-se que, embora o artigo seja destinado à saúde, aborda também a questão dos direitos sexuais sob a ótica educacional. Finalmente, a Lei n. 13.146/2015, que institui o Estatuto da Pessoa com Deficiência, prevê que "a deficiência não afeta a plena capacidade civil da pessoa", inclusive para "exercer direitos sexuais e reprodutivos" (art. $6^{\circ}$, II).

Em comparação com os demais poderes, análise da jurisprudência dos tribunais de cúpula revela que o uso da expressão é ainda mais incipiente no Poder Judiciário. No STF, foi empregada em apenas duas decisões, apenas uma no Pleno, em 2012: ${ }^{35}$ o julgamento

35 A busca de jurisprudência do STF não abarca o inteiro teor dos acórdãos, mas tão somente sua ementa e os indexadores utilizados. Disponível em: https://portal.stf.jus.br/jurisprudencia/. Acesso em: 20 dez. 2018. 
relativo ao aborto de fetos anencefálicos. ${ }^{36} \mathrm{Na}$ ocasião, foi utilizada tanto por parte do relator, Ministro Marco Aurélio, quanto no voto do Ministro Cezar Peluso, que restou vencido. Recentemente, o termo "direitos sexuais" foi empregado na ementa do julgamento da Primeira Turma do STF que declarou incidentalmente a inconstitucionalidade da criminalização do aborto até doze semanas de gestação. ${ }^{37}$ Em ambos os casos, a expressão foi utilizada em conjunto com direitos reprodutivos sem que seu sentido fosse explicitado e sem que fossem traçadas diferenciações entre o elemento sexual e o reprodutivo. Nas duas oportunidades, falou-se de "direitos sexuais e reprodutivos" tendo por objeto direitos de mulheres. No STJ, por sua vez, não há decisão colegiada que empregue o termo, mas tão somente dezesseis decisões monocráticas: ${ }^{38}$ uma sobre direito de visitação de preso, que utiliza a expressão “direitos sexuais e reprodutivos" ao parafrasear o parecer do Ministério Público, ${ }^{39}$ e quinze sobre violência doméstica, em que se reproduz o trecho supramencionado da Lei Maria da Penha. ${ }^{40}$ 28.02.2018; ST]. REsp n. 1.688.407-MS (2017/0199291-5). Decisão Monocratica. Relator Min. Nefi Cordeiro, julg. 25.08.2018, DJe 30.08.2017; STJ. HC n. 368.227-SP (2016/0219373-6). Decisão Monocrática. Relator Min. Reynaldo Soares da Fonseca, julg. 15.08.2016, DJe 19.08.2016; STJ. REsp n. 1.509.479-RN (2015/0014815-4). Decisão Monocrática. Relator Min. Nefi Cordeiro, julg. 11.02.2016, DJe 26.02.2016; STJ. AgREsp n. 526.416-DF (2014/0135468-3). Decisão Monocrática. Relator Min. Walter de Almeida Guilherme (Desembargador convocado do TJ/SP), julg. 10.11.2014, DJe 13.11.2014; STJ. CC n. 106.789-MG (2009/0143433-9). Decisão Monocrática. Relator Min. Napoleão Nunes Maia Filho, julg. 25.08.2009, DJe 01.09.2009; STJ. CC n. 102.622-MG (2009/0012457-6). Decisão Monocrática. Relatora Min. Laurita Vaz, julg. 04.08.2009, DJe 18.08.2009; STJ. CC n. 105.917-MG (2009/0112003-7). Decisão Monocrática. Relatora Min. Laurita Vaz, julg. 03.08.2009, DJe 13.08.2009; STJ. CC n. 99.349-MG (2008/0223497-0). Decisão Monocrática. Relator Min. Napoleão Nunes Maia Filho, julg. 29.06.2009, DJe 04.08.2009; STJ. CC n. 105.239-MG (2009/0091678-0). Decisão Monocrática. Relator Min. Napoleão Nunes Maia Filho, julg. 23.06.2009, DJe 03.08.2009; STJ. CC n. 104.765-MG (2009/0071625-7). Decisão Monocrática. Relator Min. Napoleão Nunes Maia Filho, julg. 23.06.2009, DJe 03.08.2009; STJ. CC n. 105.233-MG (2009/0091679-1). Decisão Monocrática. Relatora Min. Laurita Vaz, julg. 26.06.2009, DJe 01.07.2009; STJ. CC n. 104.475PR (2009/0060045-6). Decisão Monocrática. Relator Min. Napoleão Nunes Maia Filho, julg. 29.05.2009, 
Em resumo, a partir da análise do emprego da expressão "direitos sexuais" no âmbito dos poderes constituídos em nível federal, pode-se perceber o ingresso dessa expressão no debate internacional, a relativa baixa incidência do uso do termo e o predomínio de sua utilização em conjunto com as ideias de direitos reprodutivos e direito das mulheres, não obstante as críticas da literatura especializada, que, desde a década de 1990, já chamava atenção para as tensões e contradições no uso do conceito.

Como visto, a principal e mais relevante exceção é o Ministério da Saúde, que, desde 2009, emprega uma definição ampla de direitos sexuais, que articula aspectos protetivos e promocionais e perspectivas tanto negativas quanto positivas da sexualidade, sem, contudo, desvinculá-la do campo da saúde. A mesma coisa ocorre com o Estatuto da Juventude, que, apesar de tratar do relevante aspecto educacional, limita sua previsão à inclusão em diversos níveis de ensino de temas relativos à "saúde sexual e reprodutiva".

Por fim, chama atenção a ausência do emprego da expressão em contextos em que direitos relativos à sexualidade e à identidade de gênero foram amplamente discutidos, por exemplo na promulgação do Plano Nacional de Promoção da Cidadania e Direitos Humanos LGBT pelo poder Executivo em 2009 e em julgamentos do STF, como naqueles em que foram afirmados a constitucionalidade das uniões homoafetivas, em 2011, o direito à retificação de nome e sexo no registro civil de pessoas trans, em 2018, e a criminalização da LGBTfobia, em 2019.

\section{CONSIDERAÇÕES FINAIS}

A gênese da expressão "direitos sexuais" revela um conflito entre estratégias e visões sobre o seu conteúdo, articuladas, de um lado, a partir dos direitos reprodutivos e da saúde e, de outro, dos direitos ligados à sexualidade e à identidade de gênero. Analisando a trajetória do uso da expressão, observa-se - em um primeiro momento, no âmbito internacional e, ainda hoje, na esfera doméstica - uma prevalência do primeiro conjunto de direitos em instâncias institucionais, refletida na difusão da expressão "direitos sexuais e reprodutivos".

Como se demonstrou, a indiferenciação dos direitos sexuais e dos direitos reprodutivos tem o potencial de subordinar e condicionar os primeiros aos segundos, invisibilizando-os. Dessa forma, a abordagem de sexualidade e da identidade de gênero é limitada a uma visão médica e/ou cis-heteornormativa, impactando negativamente direitos de sujeitos e grupos frequentemente já marginalizados e inviabilizando uma perspectiva mais positiva e emancipatória

DJe 04.06.2009; STJ. CC n. 104.006-MG (2009/0044478-3), Relator Min. Napoleão Nunes Maia Filho, julg. 30.04.2009, DJe 07.05.2009; STJ. CC n. 88.029-MG (2007/0171796-1). Decisão Monocrática. Relatora Min. Laurita Vaz, julg. 30.05.2008, DJe 05.06.2008. 
da sexualidade. Nesse contexto, conferir aos direitos sexuais conteúdo autônomo tem permitido não apenas abarcar e mobilizar práticas e identidades tradicionalmente excluídas, mas também conceber perspectivas contra-hegemônicas de sexualidade e gênero.

Essa diferenciação não significa, contudo, que os dois grupos de direitos existam e devam existir necessariamente em contradição. Se, de um lado, servem de contrapeso um para o outro, é importante buscar compreender como podem ser articulados de maneira complementar - em um sentido emancipatório e atento ao risco que uma abordagem fragmentária coloca para os direitos de uns, a pretexto de fazer avançar direitos de outros. Nesse sentido, a diferenciação e a demarcação de um conteúdo próprio vão ao encontro das ideias de indivisibilidade e da interdependência dos direitos humanos.

O mesmo olhar integrado e contextualizado deve ser direcionado para a própria categoria direitos sexuais. Se sua utilidade tem-se revelado ao permitir trazer à luz aspectos de sexualidade e identidade de gênero tradicionalmente obliterados ou desfavorecidos, é necessário se perguntar, por exemplo, se e em que medida seu uso é capaz de apagar dimensões mais insurgentes desses mesmos direitos (sobretudo aquelas relacionadas à identidade de gênero, que não aparece expressamente no termo). Um tratamento abstrato, idealizado ou acrítico da categoria tem potencial de incorrer nos mesmos (e quiçá novos) efeitos colaterais. Nesse sentido, uma compreensão integrada dos direitos humanos requer uma abordagem complexa, crítica e contextualizada dos seus diferentes aspectos e dimensões.

\footnotetext{
AGRADECIMENTOS

Este artigo tem origem em tese de doutorado apresentada perante o Programa de Pós-Graduação em Direito da Universidade Estadual do Rio de Janeiro (UERJ) sob orientação da Professora Jane Reis Gonçalves Pereira, a quem a autora agradece imensamente. A autora agradece também a Ligia Fabris Campos pelos comentários ao manuscrito e também aos(às) pareceristas anônimos(as) da Revista Direito GV, que ofereceram relevantes aportes ao artigo.
}

\section{REFERÊNCIAS}

ALENCAR, Emanuela Cardoso Onofre de. Violência sexual: lições da Corte Interamericana de Direitos Humanos. Justificando, 21 set. 2017. Disponível em: http://www.justificando.com/2017/09/21/ violencia-sexual-licoes-da-corte-interamericana-de-direitos-humanos/. Acesso em: 10 mar. 2020. 
ÁVILA, Maria Betânia; GOUVEIA, Taciana. Notas sobre direitos reprodutivos e direitos sexuais. In: PARKER, Richard; BARBOSA, Maria Regina (org.). Sexualidades brasileiras. Rio de Janeiro: RelumeDumará/ABIA/IMS/UERJ, 1996. p. 160-172.

BERER, Marge. Repoliticising Sexual and Reproductive Health and Rights. Reproductive Health Matters, v. 19 , n. 38, p. 4-10, nov. 2011.

BRASIL. Ministério da Saúde. Secretaria de Atenção à Saúde. Departamento de Ações Programáticas Estratégicas. Cuidando de adolescentes: orientações básicas para a saúde sexual e a saúde reprodutiva. Brasília: Ministério da Saúde, 2017.

BRASIL. Ministério da Saúde. Secretaria de Atenção à Saúde. Departamento de Ações Programáticas Estratégicas. Direitos sexuais, direitos reprodutivos e métodos anticoncepcionais. Brasília: Ministério da Saúde, 2009.

BRASIL. Ministério da Saúde. Secretaria de Atenção à Saúde. Departamento de Ações Programáticas Estratégicas. Área Técnica de Saúde da Mulher. Direitos sexuais e direitos reprodutivos: uma prioridade do governo. Brasília: Ministério da Saúde, 2005.

BUNCH, Charlotte; FRIED, Susana. Beijing '95: Moving Women's Human Rights from Margin to Center. Signs, v. 22, n. 1, p. 200-204, 1996.

CITELI, Maria Teresa. A pesquisa sobre sexualidade e direitos sexuais no Brasil (1990-2002): revisão crítica. Rio de Janeiro: Cepesc, 2005.

CORRÊA, Sonia. Gênero e sexualidade: deslocando o debate da margem para o centro. Jornal da RedeSaúde, n. 24, p. 30-34, dez. 2001.

CORREAA, Sonia. From Reproductive Health to Sexual Rights: Achievements and Future Challenges. Reproductive Health Matters, v. 5, n. 10, p. 107-116, nov. 1997.

CORRÊA, Sonia; ÁVILA, Maria Betânia. Direitos sexuais e reprodutivos - Pauta global e percursos brasileiros. In: BERQUÓ, Elza (org.). Sexo \&vida: panorama da saúde reprodutiva no Brasil. Campinas, SP: Editora da Unicamp, 2003. p. 17-78.

CORREAA, Sonia; HOWE, Cymene. Global Perspectives on Sexual Rights. In: HERDT, Gilbert; HOWE, Cymene (ed.). 21 st Century Sexualities: Contemporary Issues in Health, Education, and Rights. New York: Routledge, 2007. p. 170-173. 
CORREAA, Sonia; PETCHESKY, Rosalind. Direitos sexuais e reprodutivos: uma perspectiva feminista. Physis, v. 6, n. 1-2, p. 147-177, 1996.

EUROPEAN COURT OF HUMAN RIGHTS (ECHR). Press Unit. Gender Identity Issues. Strasbourg, out. 2018a. Disponível em: https://www.echr.coe.int/Documents/FS_Gender_identity_ENG.pdf. Acesso em: 15 nov. 2018.

EUROPEAN COURT OF HUMAN RIGHTS (ECHR). Press Unit. Sexual Orientation Issues. Strasbourg, jun. 2018b. Disponível em: https://www.echr.coe.int/Documents/FS_Sexual_orientation_ENG.pdf. Acesso em: 15 nov. 2018.

EUROPEAN COURT OF HUMAN RIGHTS (ECHR). Press Unit. Homosexuality: Criminal Aspects. Strasbourg, jun. 2014. Disponível em: https://www.echr.coe.int/Documents/FS_Homosexuality_ ENG.pdf. Acesso em: 15 nov. 2018.

EUROPEAN COURT OF HUMAN RIGHTS (ECHR). Research Division. Child Sexual Abuse and Child Pornography in the Court's Case-law. Strasbourg, jun. 2011. Disponível em: https://www. echr.coe. int/Documents/Research_report_child_abuse_ENG.pdf. Acesso em: 15 nov. 2018.

GALVÃO, Jane. Aids no Brasil: a agenda de construção de uma epidemia. Rio de Janeiro: ABIA, 2000.

GIRARD, Françoise. Advocacy for Sexuality and Women's Rights: Continuities, Discontinuities, and Strategies Since ICPD. In: REICHENBACH, Laura; ROSEMAN, Mindy Jane (org.). Reproductive Health and Human Rights: The Way Forward. Filadélfia: University of Pennsylvania Press, 2009. p. 167-181.

GIRARD, Françoise. Negotiating Sexual Rights and Sexual Orientation at the United Nations. In: PARKER, Richard; PETCHESKY, Rosalind; SEMBER, Robert (org.). Sex Politics: Report from the Front Lines, 2007. p. 311-358.

HEILBORN, Maria Luiza. Editorial. Estudos Feministas, v. 3, n. 2, p. 414-426, jul./dez. 1995.

INTERNATIONAL COMMISSION OF JURISTS. Sexual Orientation, Gender Identity and Justice: A Comparative Law Casebook. Genebra: ICJ, 2011.

INTERNATIONAL PLANNED PARENTHOOD FEDERATION (IPPF). Sexual Rights: An IPPF Declaration. London: IPPF, 2008.

JOHnSON, Jeanette H.; TURNBULL, Wendy. The Women's Conference: Where Aspirations and Realities Met. Family Planning Perspectives, v. 27, n. 6, p. 254-258, nov./dez. 1995. 
JORNAL DA REDESAÚDE, n. 24, dez. 2001. Disponível em: http:/ / docplayer.com.br/31957506Jornal-da-redesaude-no-24-dezembro-de-2001.html. Acesso em: 31 jan. 2020.

LAMMASNIEMI, Laura. Anti-White Slavery Legislation and its Legacies in England. Anti-Trafficking Review, v. 9, p. 64-76, 2017.

LOTTES, Ilsa L. Sexual Rights: Meanings, Controversies, and Sexual Health Promotion. Journal of Sex Research, v. 50, n. 3-4, p. 367-391, 2013.

MACHADO, Lia Zanotta. Beijing em balanço: confrontos políticos e desafios intelectuais. Estudos Feministas, v. 3, n. 2, p. 414-426, jul./dez. 1995.

MACKINNON, Catharine. Defining Rape Internationally: A Comment on Akayesu. Columbia Journal of Transnational Law, v. 44, n. 3, p. 940-958, 2006.

MACKINNON, Catharine. Remedies for War Crimes at the National Level. The Journal of the International Institute, v. 6, n. 1, 1998.

MATTAR, Laura Davis. Reconhecimento jurídico dos direitos sexuais: uma análise comparativa com os direitos reprodutivos. Sur, Revista Internacional de Direitos Humanos, v. 5, n. 8, p. 60-83, jun. 2008.

MILLER, Alice M. Fighting Over the Figure of Gender. Pace Law Review, v. 31, n. 3, p. 837-872, jun. 2011.

MILLER, Alice M. Sexual but Not Reproductive: Exploring the Junction and Disjunction of Sexual and Reproductive Rights. Health and Human Rights, v. 4, n. 2, p. 68-109, 2000.

MILLER, Alice M. Human Rights and Sexuality: First Steps Toward Articulating a Rights Framework for Claims to Sexual Rights and Freedom. Proceedings of the ASIL Annual Meeting, v. 93, p. 288-303, 1999.

MILLER, Alice M.; KISMÖDI, Eszter; COTTINGHAM, Jane; GRUSKIN, Sofia. Sexual Rights as Human Rights: A Guide to Authoritative Sources and Principles for Applying Human Rights to Sexuality and Sexual Health. Reproductive Health Matters, v. 23, n. 46, p. 16-30, 2015.

MILLER, Alice M.; ROSEMAN, Mindy J. Normalizing Sex and its Discontents: Establishing Sexual Rights in International Law. Harvard Journal of Law and Gender, v. 34, p. 313-375, 2011 a.

MILLER, Alice M.; ROSEMAN, Mindy J. Sexual and Reproductive Rights at the United Nations: Frustration or Fulfilment? Reproductive Health Matters, v. 19, n. 38, p. 102-118, nov. 2011 b. 
MILLER, Alice M.; ROSGA, Ann Janette; SATTERHWAITE, Meg. Health, Human Rights and Lesbian Existence. Health and Human Rights, v. 1, n. 4, p. 428-448, 1995.

PETCHESKY, Rosalind P. The Language of "Sexual Minorities" and the Politics of Identity: A Position Paper. Reproductive Health Matters, v. 17, n. 33, p. 105-110, maio 2009.

PETCHESKY, Rosalind P. Sexual Rights: Inventing a Concept, Mapping an International Practice. In: BLASIUS, Mark (ed.). Sexual Identities, Queer Politics. Princeton/Oxford: Princeton University Press, 2001. p. 118-140.

PETCHESKY, Rosalind P. Human Rights, Reproductive Health and Economic Justice: Why They Are Indivisible. Reproductive Health Matters, v. 8, n. 15, p. 12-17, maio 2000.

PETCHESKY, Rosalind P. Direitos sexuais: um novo conceito na prática política internacional. In: BARBOSA, Regina Maria; PARKER, Richard (org.). Sexualidades pelo avesso: direitos, identidade e poder. Rio de Janeiro: IMS/UERJ; São Paulo: Ed. 34, 1999. p. 15-38.

PETCHESKY, Rosalind P. From Population Control to Reproductive Rights: Feminist Fault Lines. Reproductive Health Matters, v. 3, n. 6, p. 152-161, nov. 1995.

RIOS, Roger Raupp. Notas para o desenvolvimento de um direito democrático da sexualidade. In: RIOS, Roger Raupp (org.). Em defesa dos direitos sexuais. Porto Alegre: Livraria do Advogado, 2007. p. 13-38.

RIOS, Roger Raupp. Para um Direito democrático da sexualidade. Horizontes Antropológicos, n. 26, p. 71-100, jul./dez. 2006.

RIOS, Roger Raupp. A homossexualidade e a discriminação por orientação sexual no Direito brasileiro. Revista de Informação Legislativa, n. 38, v. 149, p. 279-295, 2001.

RIOS, Roger Raupp; RESADORI, Alice Hertzog; LEIVAS, Paulo Gilberto Cogo; SCHAFER, Gilberto. O Sistema Interamericano de Direitos Humanos e a discriminação contra pessoas LGBTTI: panorama, potencialidade e limites. Revista Direito e Práxis, v. 8, n. 2, p. 1545-1576, 2017.

ROTHSCHILD, Cynthia. NotYour Average Sex Story: Critical Issues in Recent Human Rights Reporting Related to Sexuality. Health and Human Rights, v. 7, n. 2, p. 165-177, 2004.

SAIZ, Ignacio. Bracketing Sexuality: Human Rights and Sexual Orientation: A Decade of Development and Denial at the UN. Health and Human Rights, v. 7, n. 2, p. 49-80, 2004. 
SCHUMAHER, Maria Aparecida. América Latina mais integrada. Estudos Feministas, v. 3, n. 2, p. 414426, jul./dez. 1995.

SOARES, Gilberta Santos. Direitos sexuais como direitos humanos: um convite à reflexão. Jornal da RedeSaúde, n. 24, dez. 2001.

THEYogyakarta Principles. Principles and State Obligations on the Application of International Human Rights Law in Relation to Sexual Orientation, Gender Identity, Gender Expression and Sex Characteristics to Complement theYogyakarta Principles. 2006. Disponível em: www.yogyakartaprinciples.org. Acesso em: 10 nov. 2021.

VENTURA, Miriam. Direitos reprodutivos no Brasil. São Paulo: Fundação MacArthur, 2002.

VIANNA, Adriana; LACERDA, Paula. Direitos e políticas sexuais no Brasil: mapeamento e diagnóstico. Rio de Janeiro: Cepesc, 2004.

WILSON, Ara. Lesbian Visibility and Sexual Rights at Beijing. Signs, v. 22, p. 214-218, 1996.

WORLD ASSOCIATION FOR SEXUAL HEALTH (WAS). Declaration of Sexual Rights. ed. rev., 2014. Disponível em: https://worldsexualhealth.net/wp-content/uploads/2021/09/declaration_of_sexual_ rights_sep03_2014_b.pdf. Acesso em: 5 nov. 2021.

WORLD HEALTH ORGANIZATION (WHO). Sexual Health, Human Rights and the Law. Reproductive Health Matters, v. 23, n. 46, p. 193-195, 2015.

WORLD HEALTH ORGANIZATION (WHO). Developing Sexual Health Programmes: A Framework for Action. Genebra, 2010. Disponível em: https://www.who.int/reproductivehealth/publications / sexual_health/rhr_hrp_10_22/en/.Acesso em: 3 fev. 2020.

WORLD PROFESSIONAL ASSOCIATION FOR TRANSGENDER HEALTH (WPATH). Standards of Care for the Health of Transsexual, Transgender, and Gender Nonconforming People. 7th version, 2012. Disponível em: https://www.wpath.org/publications/soc. Acesso em: 20 dez. 2018. 


\section{COMO CITAR ESTE ARTIGO:}

GOMES, Juliana Cesario Alvim. Direitos sexuais e reprodutivos ou direitos sexuais e direitos reprodutivos? Dilemas e contradições nos marcos normativos nacionais e internacionais. Revista Direito GV, São Paulo, v. 17, n. 3, set./dez. 2021, e2136. https://doi.org/ 10.1590/2317-6172202136

\section{Juliana Cesario Alvim Gomes}

Professora Adjunta de Direitos Humanos da Universidade Federal de Minas Gerais (UFMG). CoORdenadora da Clínica de Direitos humanos da UFMG. Doutora e Mestre em Direito Público Pela Universidade Estadual do RIO dE Janeiro (UERJ). LL.M. Pela Yale LaW SchoOL. Bacharel EM DiReito PELA UERJ E em CiênCIAS SociaIS PELA Universidade Federal do RIO de JANEIRo (UFRJ). julianacesarioalvimaufmg.br 